Virginia Commonwealth University VCU Scholars Compass

2010

\title{
Electronic structure and properties of isoelectronic magic clusters: $\operatorname{Al} 13 \mathrm{X}(\mathrm{X}=\mathrm{H}, \mathrm{Au}, \mathrm{Li}, \mathrm{Na}, \mathrm{K}, \mathrm{Rb}, \mathrm{Cs})$
}

Yeon Jae Ko

Johns Hopkins University

Anisha Shakya

McNeese University

Haopeng Wang

Johns Hopkins University

See next page for additional authors

Follow this and additional works at: http://scholarscompass.vcu.edu/phys_pubs

Part of the Physics Commons

Ko, Y. J., Shakya, A., Wang, H., et al. Electronic structure and properties of isoelectronic magic clusters: Al13X (X=H,Au,Li,Na,K,Rb,Cs). The Journal of Chemical Physics 133, 124308 (2010). Copyright (C) 2010 AIP Publishing LLC.

\section{Downloaded from}

http://scholarscompass.vcu.edu/phys_pubs/115

This Article is brought to you for free and open access by the Dept. of Physics at VCU Scholars Compass. It has been accepted for inclusion in Physics Publications by an authorized administrator of VCU Scholars Compass. For more information, please contact libcompass@vcu.edu. 
Authors

Yeon Jae Ko, Anisha Shakya, Haopeng Wang, Andrej Grubisic, Weijun Zheng, Matthias Gotz, Gerd Gantefor, Kit H. Bowen, Puru Jena, and Boggavarapu Kiran 


\title{
Electronic structure and properties of isoelectronic magic clusters: $\mathrm{Al}_{13} \mathrm{X}(\mathrm{X}=\mathrm{H}, \mathrm{Au}, \mathrm{Li}, \mathrm{Na}, \mathrm{K}, \mathrm{Rb}, \mathrm{Cs})$
}

\author{
Yeon Jae Ko, ${ }^{1}$ Anisha Shakya, ${ }^{2}$ Haopeng Wang, ${ }^{1}$ Andrej Grubisic, ${ }^{1}$ Weijun Zheng, ${ }^{1}$ \\ Matthias Götz, ${ }^{3}$ Gerd Ganteför, ${ }^{3}$ Kit H. Bowen, ${ }^{\text {,a) }}$ Puru Jena, ${ }^{4}$ and Boggavarapu Kiran ${ }^{2, b)}$ \\ ${ }^{1}$ Department of Chemistry, Johns Hopkins University, Baltimore, Maryland 21209, USA \\ ${ }^{2}$ Department of Chemistry, McNeese University, Lake Charles, Louisiana 70609, USA \\ ${ }^{3}$ Department of Physics, Konstanz University, 78457 Konstanz, Germany \\ ${ }^{4}$ Department of Physics, Virginia Commonwealth University, Virginia 23205, USA
}

(Received 19 May 2010; accepted 26 August 2010; published online 24 September 2010)

\begin{abstract}
The equilibrium structure, stability, and electronic properties of the $\mathrm{Al}_{13} \mathrm{X}$ ( $\mathrm{X}$ $=\mathrm{H}, \mathrm{Au}, \mathrm{Li}, \mathrm{Na}, \mathrm{K}, \mathrm{Rb}, \mathrm{Cs}$ ) clusters have been studied using a combination of photoelectron spectroscopy experiment and density functional theory. All these clusters constitute 40 electron systems with 39 electrons contributed by the $13 \mathrm{Al}$ atoms and 1 electron contributed by each of the $\mathrm{X}(\mathrm{X}=\mathrm{H}, \mathrm{Au}, \mathrm{Li}, \mathrm{Na}, \mathrm{K}, \mathrm{Rb}, \mathrm{Cs})$ atom. A systematic study allows us to investigate whether all electrons contributed by the $\mathrm{X}$ atoms are alike and whether the structure, stability, and properties of all the magic clusters are similar. Furthermore, quantitative agreement between the calculated and the measured electron affinities and vertical detachment energies enable us to identify the ground state geometries of these clusters both in neutral and anionic configurations. (C) 2010 American Institute of Physics. [doi:10.1063/1.3490401]
\end{abstract}

\section{INTRODUCTION}

The discovery of conspicuous peaks in the mass spectra of $\mathrm{Na}_{\mathrm{n}}$ clusters at $\mathrm{n}=2,8,20,40, \ldots$ a quarter century ago and their resemblance to magic numbers in nuclei has led to considerable interest in studying clusters of simple metals. ${ }^{1}$ By assuming that the electronic structure of simple metal clusters behave much the same way as they do in the bulk, namely, as nearly free electrons, Knight and co-workers ${ }^{1,2}$ were able to explain the origin of the magic numbers in $\mathrm{Na}$ clusters as due to electronic shell closure. This work has since stimulated numerous experiments and theoretical calculations where magic clusters were designed and formed by varying not only their size and composition but also their charge state. ${ }^{3,4}$ One such element where much of this investigation has concentrated is aluminum. It was shown that $\mathrm{Al}_{13}{ }^{-}$, which contains 40 electrons, possesses the same properties as that of a magic cluster and it is chemically more inert than its neighbors. ${ }^{5}$ Later work showed that magic clusters can also be created by tailoring their composition. For example, $\mathrm{Al}_{13} \mathrm{M}(\mathrm{M}=$ an alkali metal atom), which also contains 40 electrons, can be a magic cluster and its stability is characterized by an ionic bond between $\mathrm{Al}_{13}{ }^{-}$and $\mathrm{M}^{+}$. ${ }^{6-9}$

In this work, we have systematically studied the equilibrium structure, stability, and electron affinities of $\mathrm{Al}_{13} \mathrm{X}(\mathrm{X}$ $=\mathrm{H}, \mathrm{Au}, \mathrm{Li}, \mathrm{Na}, \mathrm{K}, \mathrm{Rb}$, and $\mathrm{Cs}$ ) clusters using both density functional theory and photoelectron spectroscopy experiments. We note that each of the $\mathrm{H}, \mathrm{Au}$, and $\mathrm{Li}-\mathrm{Cs}$ atoms have one valance electron that can potentially participate in the overall bonding of the $\mathrm{Al}_{13} \mathrm{X}$ cluster, yet these electrons are not alike; they originate from different atomic orbitals and

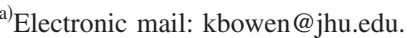

${ }^{b)}$ Electronic mail: kiran@mcneese.edu.
}

the electronic structures of these atoms are also different. For example, earlier photoelectron spectroscopy experiments demonstrated that hydrogen atoms share similar properties with gold, ${ }^{10-13}$ while recent work has shown that the structure of boric acid, $\mathrm{B}(\mathrm{OH})_{3}$, is very different from its isoelectronic analog $\left(\mathrm{BO}_{3} \mathrm{Au}_{3}\right) \cdot{ }^{14} \mathrm{In}$ a similar vein, $\mathrm{H}$ behaves as an $\mathrm{H}^{-}$ion when embedded in a metal, while the alkali atoms form salts, and the behavior of gold is not completely understood. Since all these one electron atoms possess wildly different electron affinities, it is interesting to investigate the structure and properties of the $\mathrm{Al}_{13} \mathrm{X}$ clusters. Some of the systems undertaken here have been studied either through experiments or by computations elsewhere. Anion photoelectron spectroscopic studies on $\mathrm{Al}_{13} \mathrm{X}\left[\mathrm{X}=\mathrm{Li},{ }^{15} \mathrm{~K},{ }^{8} \mathrm{Cs},{ }^{16}\right.$ and $\left.\mathrm{H}^{17}\right)$ ] by the groups of Bowen, Nakajima, and Ganteför identified large HOMO-LUMO gaps in these systems. Similarly through computations, Jena's group ${ }^{18}$ and $\mathrm{Kumar}^{19}$ studied $\mathrm{Al}_{13} \mathrm{X}(\mathrm{X}=\mathrm{Li}-\mathrm{Cs})$ and $\mathrm{Al}_{13} \mathrm{Na}$, respectively, as possible candidates for cluster-assembled materials. In this report, we include the $\mathrm{Al}_{13} \mathrm{Na}, \mathrm{Al}_{13} \mathrm{Rb}$, and $\mathrm{Al}_{13} \mathrm{Au}$ systems and provide a comprehensive understanding. To understand similarities between the 40 valence electrons in $\mathrm{Al}_{13} \mathrm{X}$ (X $=\mathrm{H}, \mathrm{Au}, \mathrm{Li}-\mathrm{Cs}$ ), we have carried out complementary photoelectron spectroscopy experiments and density functional theory-based calculations.

\section{METHODS}

\section{A. Experimental}

Anion photoelectron spectroscopy is conducted by crossing a mass-selected, negative ion beam with a fixed-energy photon beam and analyzing the energies of the resultant photodetached electrons. This technique is governed by the wellknown energy-conserving relationship, $\mathrm{h} \nu=\mathrm{EBE}+\mathrm{EKE}$, 
where $\mathrm{h} \nu, \mathrm{EBE}$, and EKE are the photon energy, electron binding energy (transition energy), and the electron kinetic energy, respectively.

Our photoelectron instruments, which have been described elsewhere ${ }^{20}$ consist of an ion source, a linear timeof-flight mass spectrometer, a mass gate, a momentum decelerator, a neodymium-doped yttrium aluminum garnet (Nd:YAG) laser operated at various harmonics for photodetachment, and a magnetic bottle electron energy analyzer with a resolution of $35 \mathrm{meV}$ at $\mathrm{EKE}=1 \mathrm{eV}$. The photoelectron spectra were calibrated against the well-known photoelectron spectrum of $\mathrm{Cu}^{-}$.

Four approaches to cluster anion generation were used in order to measure the photoelectron spectra of $\mathrm{Al}_{13} \mathrm{H}^{-}$, $\mathrm{Al}_{13} \mathrm{Au}^{-}, \mathrm{Al}_{13} \mathrm{Li}^{-}, \mathrm{Al}_{13} \mathrm{Na}^{-}, \mathrm{Al}_{13} \mathrm{~K}^{-}, \mathrm{Al}_{13} \mathrm{Rb}^{-}$, and $\mathrm{Al}_{13} \mathrm{Cs}^{-}$. The cluster anions, $\mathrm{Al}_{13} \mathrm{H}^{-}, \mathrm{Al}_{13} \mathrm{Au}^{-}$, and $\mathrm{Al}_{13} \mathrm{Na}^{-}$, were all generated in a pulsed arc cluster ionization source that has been described in detail elsewhere. ${ }^{21}$ Briefly, a discharge is triggered between an anode and a cathode that vaporizes the sample from the cathode. A copper rod was used as the anode. The cathode was prepared by mixing and pressing aluminum powder with gold powder or sodium metal into a well, which was drilled on the top surface of an aluminum rod. Helium gas propels the resultant plasma into a flow tube, where the evaporated sample material cools and forms cluster. $\mathrm{Al}_{13} \mathrm{Au}^{-}$was also generated by using a two-laser vaporization source described elsewhere. ${ }^{22}$ Briefly, two independent lasers ablate material from two different rods mounted on opposite sides of a horizontal channel. An aluminum rod was positioned downstream and ablated with 532 $\mathrm{nm}$ laser light from a Nd:YAG laser. A gold foil was wrapped around an aluminum mandrel to act as a gold "rod." This rod was ablated by a combination of 1064 and $532 \mathrm{~nm}$ light from a Nd:YAG laser ( $5 \mu$ s earlier than the first laser) which lacked the dichroic mirrors to separate the two harmonics. Helium gas propels the plasma mix into a flow channel resulting in cluster formation. The cluster anions, $\mathrm{Al}_{13} \mathrm{Na}^{-}$, $\mathrm{Al}_{13} \mathrm{~K}^{-}, \mathrm{Al}_{13} \mathrm{Rb}^{-}$, and $\mathrm{Al}_{13} \mathrm{Cs}^{-}$, were generated in a Smalleytype laser vaporization source modified to accept a small oven in its base just below a rotating, translating aluminum rod. Laser ablation of the alkali-coated rod was accomplished with $532 \mathrm{~nm}$ light pulses from a Nd:YAG laser, and helium gas was utilized in the pulsed valve for cooling and generating clusters. Lastly, $\mathrm{Al}_{13} \mathrm{Li}^{-}$was generated in a laser vaporization source using a lithium-aluminum alloy rod as a target.

\section{B. Theoretical}

The density functional theory (DFT) calculations on $\mathrm{Al}_{13} \mathrm{X}^{0 /-1}(\mathrm{X}=\mathrm{H}, \mathrm{Li}-\mathrm{Cs}, \mathrm{Au})$ clusters were carried out by employing Becke's three parameter hybrid functional with Lee, Yang, and Parr correlation functional form and an all electron $6-311+\mathrm{G}(\mathrm{d})$ basis set for $\mathrm{Al}$ and $\mathrm{H}, \mathrm{Li}, \mathrm{Na}$, and $\mathrm{K}$ atoms. ${ }^{23}$ For $\mathrm{Cs}$ and $\mathrm{Au}$, we have used Stuttgart/Dresden SDD basis set. ${ }^{24}$ In addition, for Au one additional $f(0.748)$ polarization function was added to the SDD basis set. All calculations were carried out using the GAUSSIAN 03 code. $^{25}$

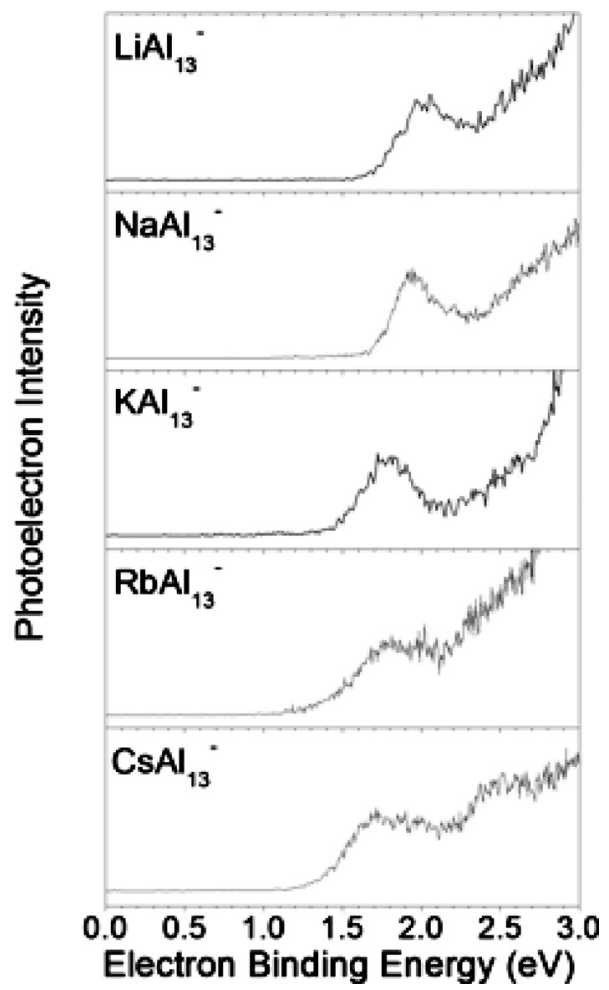

FIG. 1. Anion photoelectron spectra of $\mathrm{Al}_{13} \mathrm{Li}^{-}$(Ref. 15), $\mathrm{Al}_{13} \mathrm{Na}^{-}, \mathrm{Al}_{13} \mathrm{~K}^{-}$ (Ref. 8), $\mathrm{Al}_{13} \mathrm{Rb}^{-}$, and $\mathrm{Al}_{13} \mathrm{Cs}^{-}$measured with $3.49 \mathrm{eV}$ photons.

All the isomers reported were found to be minima on their respective potential energy surfaces.

\section{RESULTS AND DISCUSSION}

The anion photoelectron spectra of $\mathrm{Al}_{13} \mathrm{M}^{-}$(where $\mathrm{M}$ $=\mathrm{Li},{ }^{15} \mathrm{Na}, \mathrm{K},{ }^{8} \mathrm{Rb}$, and $\mathrm{Cs}$ ) are presented in Fig. 1. All these spectra exhibit qualitatively similar features. The lowest EBE band in each spectrum lies in $E B E=1.4-2.3 \mathrm{eV}$. As the masses of the alkali metal atoms (M) increase, the onsets of their lowest EBE bands shift to lower EBE values, consistent with the theoretical study of Jena's group. ${ }^{18}$ These correlate to their electron affinity values. Figure 2 presents a plot of the experimentally determined electron affinity values for the $\mathrm{Al}_{\mathrm{n}} \mathrm{M}$ clusters versus size, $\mathrm{n}$, over the range of $9 \leq \mathrm{n} \leq 15$. All these species exhibit minimum electron affinity values (a dip in the trend) at $n=13$. Moreover, the more electropositive the alkali atom, the lower the electron affinity. At higher EBE side of each spectrum, rising photoelectron intensities are observed. The energy spacing between the lower EBE band and the maxima in these higher EBE bands is indicative of the HOMO-LUMO gaps of the neutral.

Figure 3 presents the anion photoelectron spectrum of $\mathrm{Al}_{13} \mathrm{Au}^{-}$. Qualitatively, it resembles the spectra of the $\mathrm{Al}_{13} \mathrm{M}^{-}$series. It exhibits a low EBE band between 2.2 and $2.7 \mathrm{eV}$, along with a higher EBE peak at $\sim 3.3 \mathrm{eV}$. Quantitatively, its lowest EBE peak is higher in energy than the lowest EBE peaks in any of the $\mathrm{Al}_{13} \mathrm{M}^{-}$spectra. Figure 4 presents the anion photoelectron spectrum of $\mathrm{Al}_{13} \mathrm{H}^{-}$. While specifics have been published previously, ${ }^{17,26,27}$ this spectrum shows evidence for two anionic isomers, each with different 


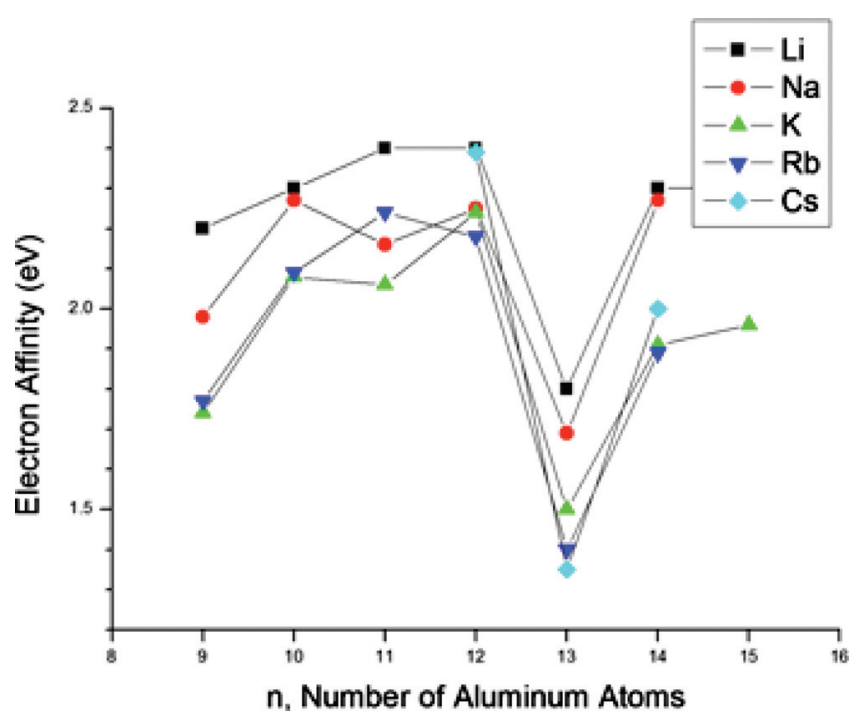

FIG. 2. The experimentally measured electron affinities of $\mathrm{Al}_{\mathrm{n}} \mathrm{M}^{-}(\mathrm{M}$ $=\mathrm{Li}, \mathrm{Na}, \mathrm{K}, \mathrm{Rb}, \mathrm{Cs}, 9 \leq \mathrm{n} \leq 15)$.

vertical detachment energies (VDEs), i.e., 2.2 and $3.15 \mathrm{eV}$. These isomers differ in the position of the lone hydrogen atom binding to the aluminum icosahedron.

In order to provide insight into the electronic structure of these three types of species, i.e., $\mathrm{Al}_{13} \mathrm{X}(\mathrm{X}=\mathrm{M}, \mathrm{H}$, and $\mathrm{Au})$, we have performed extensive calculations using density functional theory. Three categories are found: (a) ionic, (b) covalent, and (c) partially covalent. Alkali (from Li to Cs) metal atoms produce $\mathrm{Al}_{13} \mathrm{X}$ species belonging to the ionic group, in which a nearly complete transfer of electron from the metal to the aluminum moiety ensures a saltlike, chargetransferred system. Hydrogen interacts with the aluminum cluster in a covalent fashion, thus belonging to the covalent category. In the case of an icosahedral aluminum cluster (see structure 1 in Fig. 5), there are three possible ways in which a hydrogen atom can bind to the $\mathrm{Al}_{13}{ }^{-}$cluster, ${ }^{26}$ i.e., at a radial or a terminal site where the $\mathrm{H}$ atom is bound to a

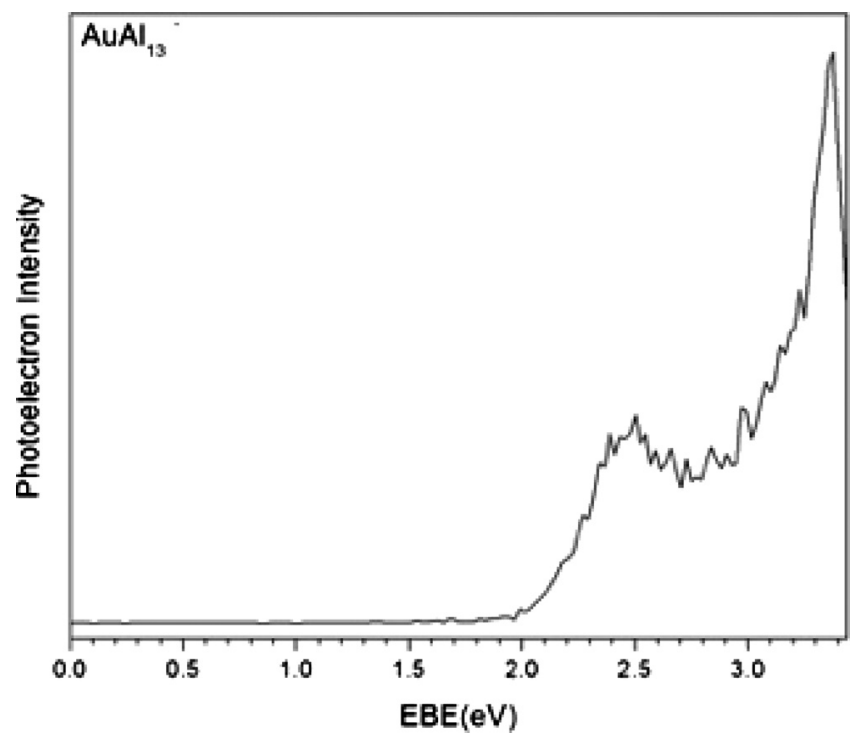

FIG. 3. Anion photoelectron spectrum of $\mathrm{Al}_{13} \mathrm{Au}^{-}$measured with $3.49 \mathrm{eV}$ photons.

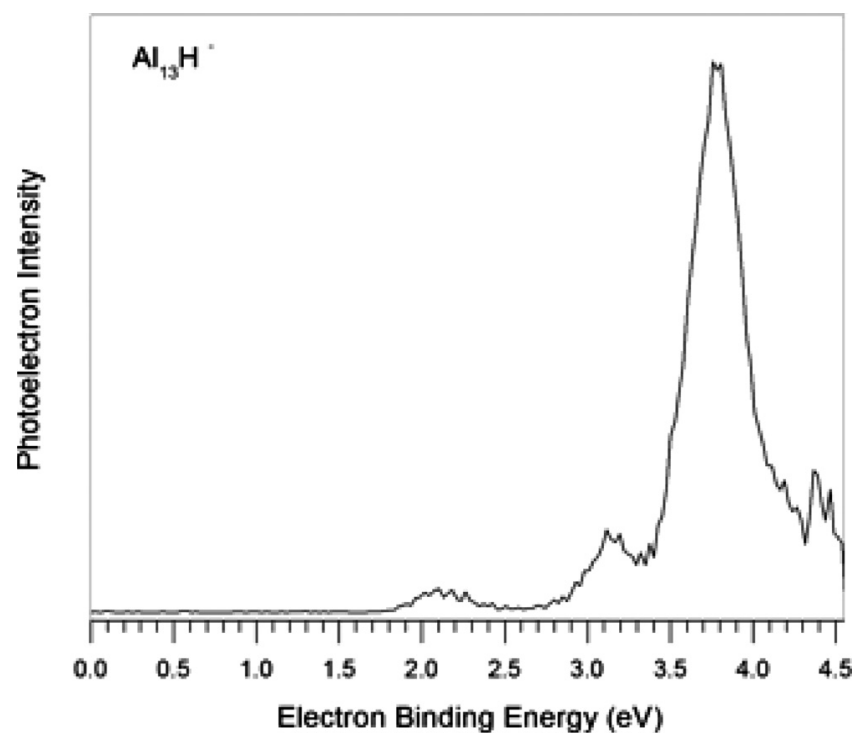

FIG. 4. Anion photoelectron spectrum of $\mathrm{Al}_{13} \mathrm{H}^{-}$(Ref. 27) measured with $4.66 \mathrm{eV}$ photons.

single $\mathrm{Al}$ atom, at a bridge site where it is bound to two $\mathrm{Al}$ atoms, or at a hollow site where it resides on the face of a triangle formed by three $\mathrm{Al}$ atoms. Gold, on the other hand, exhibits a dual nature depending on the nature of the species to which it is attached. A gold atom behaves either like an electron donor or an electron acceptor, ${ }^{25}$ depending on whether it interacts with highly electronegative or electropositive atoms, respectively. In addition, gold can also form covalent bonds with atoms of comparable electronegativity, such as silicon. ${ }^{10-13}$ In the present case, the $\mathrm{Al}-\mathrm{Au}$ bond is partially polar. Thus, the interaction between aluminum and gold falls in between the alkali and the hydrogen bonding models.

We begin the discussion with the $\mathrm{Al}_{13}$-alkali systems. The calculated $\mathrm{Al}_{13} \mathrm{M}(\mathrm{M}=\mathrm{Li}-\mathrm{Cs}$, structure 2 in Fig. 5) structures, along with critical bond distances, are given in
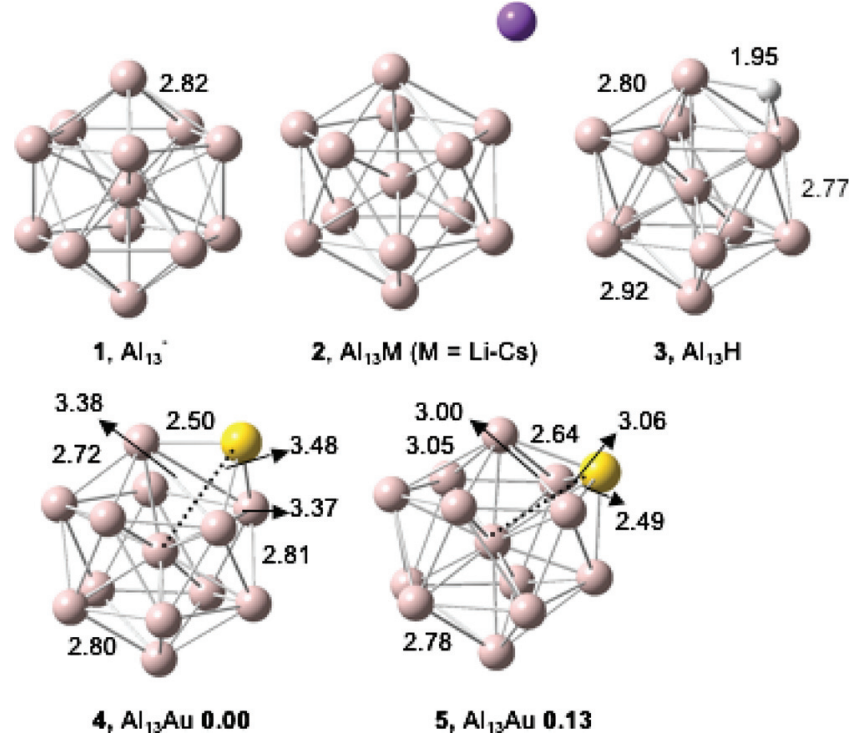

FIG. 5. The calculated lowest energy structures of (1) $\mathrm{Al}_{13}{ }^{-}$, (2) $\mathrm{Al}_{13}$-alkali, (3) $\mathrm{Al}_{13} \mathrm{H}$, (4) $\mathrm{Al}_{13} \mathrm{Au}$, and the second lowest energy structure of (5) $\mathrm{Al}_{13} \mathrm{Au}$. 
TABLE I. Average bond lengths between $\mathrm{Al}-\mathrm{Al}$ and $\mathrm{Al}-\mathrm{M}$ atoms in neutral and anionic clusters as well as the adiabatic and vertical detachment energies of the anion and HOMO-LUMO gaps of the neutral.

\begin{tabular}{|c|c|c|c|c|c|}
\hline \multirow[b]{2}{*}{ M } & \multirow{2}{*}{$\begin{array}{c}\begin{array}{c}\text { Average Al-Al } \\
(\AA)\end{array} \\
\text { Neutral/anion }\end{array}$} & \multirow{2}{*}{$\begin{array}{c}\begin{array}{c}\mathrm{Al}-\mathrm{M} \\
(\AA)\end{array} \\
\text { Neutral/anion }\end{array}$} & \multirow{2}{*}{$\begin{array}{l}\text { NBO charges } \\
\text { Neutral/anion }\end{array}$} & \multirow[b]{2}{*}{$\begin{array}{c}\text { ADE/VDE } \\
(\mathrm{eV})\end{array}$} & \multirow[b]{2}{*}{$\begin{array}{c}\text { H-L gap } \\
(\mathrm{eV})\end{array}$} \\
\hline & & & & & \\
\hline $\mathrm{Li}$ & $2.77 / 2.79$ & $2.77 / 2.76$ & $0.87 / 0.84$ & $1.81 / 1.99$ & 1.24 \\
\hline $\mathrm{Na}$ & $2.80 / 2.80$ & $3.10 / 3.06$ & $0.86 / 0.79$ & $1.71 / 1.96$ & 1.19 \\
\hline K & $2.78 / 2.81$ & $3.50 / 3.45$ & $0.94 / 0.85$ & $1.58 / 1.78$ & 1.18 \\
\hline $\mathrm{Rb}$ & $2.78 / 2.80$ & $3.83 / 3.78$ & $0.95 / 0.88$ & $1.36 / 1.52$ & 1.30 \\
\hline Cs & $2.78 / 2.80$ & $4.00 / 3.95$ & $0.98 / 0.91$ & $1.20 / 1.43$ & 1.18 \\
\hline
\end{tabular}

Table I. Two geometrical parameters are worth mentioning. First, the Al-M distances increase systematically from $\mathrm{Li}$ $(2.77 \AA)$ to $\mathrm{Cs}(4.00 \AA)$, reflecting the increasing size of the alkali atoms as we go down the series. Second, the average $\mathrm{Al}-\mathrm{Al}$ distances in both neutral and anionic $\mathrm{Al}_{13} \mathrm{M}$ for all alkali metals are remarkably similar $(2.76-2.86 \AA)$ and compare very well with the corresponding distances in icosahedral $\mathrm{Al}_{13}{ }^{-}(2.81 \AA)$ and $\mathrm{Al}_{13}{ }^{2-}(2.81 \AA)$. This constant average bond does not mean that there are no distortions in the cluster; the individual bond lengths vary from 2.65 to $3.00 \AA$ in neutral and from 2.65 to $3.32 \AA$ for anion. However, the $\mathrm{Al}_{13}$ cluster is very resilient and rearranges itself so as to maintain constant $\mathrm{Al}-\mathrm{Al}$ average bond length. The consistency in bond length variations indicates that the clusters are very similar to each other and the charge transfer from the metals to $\mathrm{Al}_{13}$ is nearly complete both in anion and neutral. NBO charge analysis clearly reflects this trend (Table I). Note that among the alkali metals $\mathrm{Li}$ is the least positive while $\mathrm{Cs}$ is the most positive.

To validate the accuracy of the computed structures of the $\mathrm{Al}_{13} \mathrm{M}$ clusters, we have calculated the adiabatic detachment energies (ADEs) and VDEs, which can be compared with the experimental data obtained from photoelectron spectroscopy. The calculated ADE (electron affinity) and VDE values compare very well with the experimental numbers and the trends are reproduced accurately. For example, the systematic decrease in the $\mathrm{ADE}$ values from $\mathrm{Al}_{13} \mathrm{Li}(1.81$ $\mathrm{eV})$ to $\mathrm{Al}_{13} \mathrm{Cs}(1.20 \mathrm{eV})$ is well reproduced in the experiments as well (Table I). Given the fact that these species are highly ionic and thus that charge transfer occurs to a high degree in all of them (both in their neutrals and anions), electron detachment energies might be expected to be the same for these species. However, both the calculated and the experimental ADEs decrease systematically in going from $\mathrm{Al}_{13} \mathrm{Li}$ to $\mathrm{Al}_{13} \mathrm{Cs}$ (see Fig. 6). Clues for understanding this can be traced back to the nature of the interaction between alkali cations and aluminum clusters. As the atomic number increases, in group I elements, the cationic size also increases, resulting in the increase of the cluster-cation distance (see Table I). Since the nature of the $\mathrm{Al}_{13}-\mathrm{M}$ interaction is mostly electrostatic, which, in turn, is inversely proportional to the distance, one would anticipate a gradual decrease of stabilization energy and thus in their corresponding electron affinities in going from $\mathrm{Al}_{13} \mathrm{Li}$ to $\mathrm{Al}_{13} \mathrm{Cs}$. To quan- tify this, we have done binding energy (BE) calculations [Eqs. (1)-(4)] for both anions and neutral $\mathrm{Al}_{13} \mathrm{X}$ clusters,

$$
\begin{aligned}
& \Delta \mathrm{E}_{1}{ }^{0}=-\left[\mathrm{E}\left(\mathrm{Al}_{13} \mathrm{M}\right)-\mathrm{E}\left(\mathrm{Al}_{13}{ }^{-}\right)-\mathrm{E}\left(\mathrm{M}^{+}\right)\right], \\
& \Delta \mathrm{E}_{2}{ }^{0}=-\left[\mathrm{E}\left(\mathrm{Al}_{13} \mathrm{M}\right)-\mathrm{E}\left(\mathrm{Al}_{13}\right)-\mathrm{E}(\mathrm{M})\right], \\
& \Delta \mathrm{E}_{3}{ }^{-}=-\left[\mathrm{E}\left(\mathrm{Al}_{13} \mathrm{M}^{-}\right)-\mathrm{E}\left(\mathrm{Al}_{13}{ }^{2-}\right)-\mathrm{E}\left(\mathrm{M}^{+}\right)\right], \\
& \Delta \mathrm{E}_{4}{ }^{-}=-\left[\mathrm{E}\left(\mathrm{Al}_{13} \mathrm{M}^{-}\right)-\mathrm{E}\left(\mathrm{Al}_{13}{ }^{-}\right)-\mathrm{E}(\mathrm{M})\right] .
\end{aligned}
$$

We have considered four equations to calculate the binding energy - each reflecting how the alkali metal interacts with the $\mathrm{Al}_{13}$ cluster. Equations (1) and (3) reflect the interaction energy between alkali cations with $\mathrm{Al}_{13}{ }^{-}$and $\mathrm{Al}_{13}{ }^{2-}$ clusters, respectively. This is a valid partition considering the fact that there is nearly complete charge transfer from the alkali metals in both neutrals and anions (Table I). On the other hand, in Eqs. (2) and (4), the alkali metals are treated as atoms interacting with the corresponding aluminum cluster. All the calculated energies from the above equations are given in Table II. There is a genuine but indirect correlation between the electron affinities and the binding energies. Consider the binding energy difference between Eqs. (2) and (4) (i.e., $\left.\Delta \mathrm{E}_{2-4}=\Delta \mathrm{E}_{2}{ }^{0}-\Delta \mathrm{E}_{4}{ }^{-}\right)$. This energy corresponds to the differ-

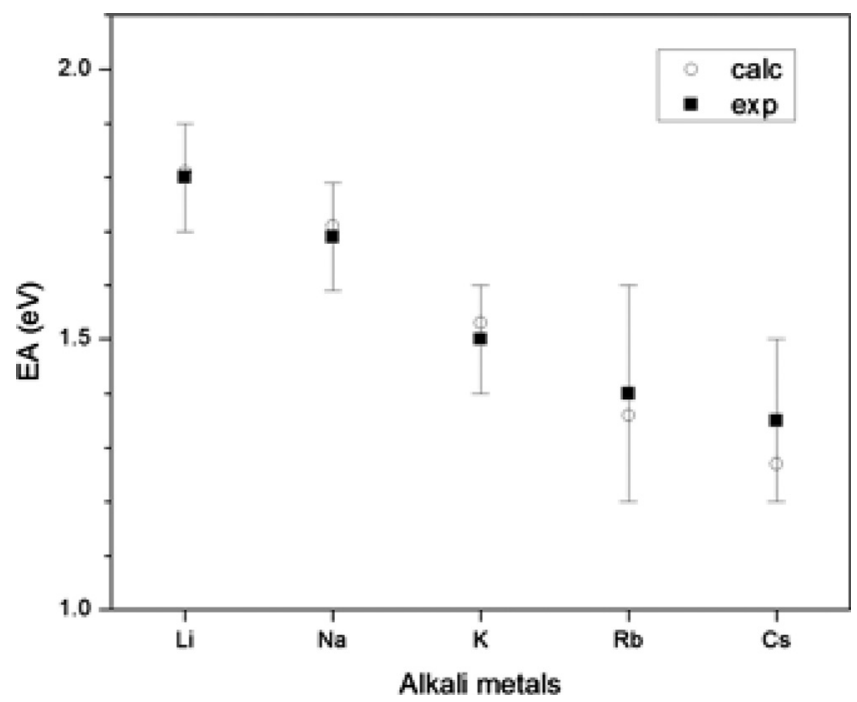

FIG. 6. Comparison of experimental and theoretical electron affinity trends for the $\mathrm{Al}_{13} \mathrm{M}(\mathrm{M}=\mathrm{Li}, \mathrm{Na}, \mathrm{K}, \mathrm{Rb}, \mathrm{Cs})$ clusters. 
TABLE II. Binding energies of neutral and anionic $\mathrm{Al}_{13} \mathrm{M}$ clusters defined in Eqs. (1)-(4).

\begin{tabular}{llllll}
\hline \hline $\mathrm{M}$ & $\begin{array}{c}\Delta \mathrm{E}_{1}{ }^{0} \\
(\mathrm{eV})\end{array}$ & $\begin{array}{c}\Delta \mathrm{E}_{2}{ }^{0} \\
(\mathrm{eV})\end{array}$ & $\begin{array}{c}\Delta \mathrm{E}_{3}{ }^{-} \\
(\mathrm{eV})\end{array}$ & $\begin{array}{c}\Delta \mathrm{E}_{4}^{-} \\
(\mathrm{eV})\end{array}$ & $\begin{array}{c}\Delta \mathrm{E}_{2-4} \\
(\mathrm{eV})\end{array}$ \\
\hline $\mathrm{Li}$ & 4.94 & 2.53 & 8.00 & 1.13 & 1.40 \\
$\mathrm{Na}$ & 4.30 & 2.10 & 7.26 & 0.59 & 1.50 \\
$\mathrm{~K}$ & 3.50 & 2.22 & 6.28 & 0.54 & 1.68 \\
$\mathrm{Rb}$ & 3.19 & 2.07 & 5.79 & 0.22 & 1.85 \\
$\mathrm{Cs}$ & 2.94 & 2.14 & 5.46 & 0.20 & 1.94 \\
\hline \hline
\end{tabular}

ence in the electron affinities of $\mathrm{Al}_{13} \mathrm{M}^{-}$and $\mathrm{Al}_{13}{ }^{-}$(i.e., $\Delta \mathrm{E}_{2-4}=\left[-\mathrm{EA}_{\mathrm{Al}_{13} \mathrm{M}}+\mathrm{EA}_{\mathrm{Al}_{13}-}\right]$, in which $\mathrm{EA}_{\mathrm{Al}_{13} \mathrm{M}}=\left[\mathrm{E}\left(\mathrm{Al}_{13} \mathrm{M}\right)\right.$

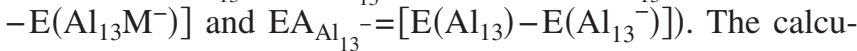
lated values from $\mathrm{Li}$ to $\mathrm{Cs}$ are given in Table II. Now, consider that the difference between $\Delta \mathrm{E}_{2-4}$ values for $\mathrm{Li}$ and $\mathrm{Cs}$, which is $0.54 \mathrm{eV}$, is exactly the difference in the EAs of $\mathrm{Al}_{13} \mathrm{Li}$ and $\mathrm{Al}_{13} \mathrm{Cs}$ (Table I). Therefore, EAs for a series of isoelectronic systems do reflect the nature of bonding.

Certain trends are clearly indicated in Table II. First, the $\mathrm{BE}$ of the $\mathrm{Al}_{13} \mathrm{M}$ clusters, in both neutral and anion charged states, decreases systematically from $\mathrm{Al}_{13} \mathrm{Li}$ to $\mathrm{Al}_{13} \mathrm{Cs}$. Second, that decrease is independent of the way in which $\mathrm{BE}$ is calculated. In other words, Li provides highest stabilization and $\mathrm{Cs}$ the least, irrespective of the methods used for binding energy calculations. Most importantly, the decrease in the BE for anions is steeper than for the neutrals. For example, the variation in $\Delta \mathrm{E}_{1}{ }^{0}$ values in going from neutral $\mathrm{Al}_{13} \mathrm{Li}$ to $\mathrm{Al}_{13} \mathrm{Cs}(2.00 \mathrm{eV})$ is less than the variation in $\Delta \mathrm{E}_{3}{ }^{-}$values in going from anionic $\mathrm{Al}_{13} \mathrm{Li}^{-}$to $\mathrm{Al}_{13} \mathrm{Cs}^{-}(2.54 \mathrm{eV})$. This indicates that anions, in comparison to neutrals, are more destabilized in going from $\mathrm{Al}_{13} \mathrm{Li}^{-}$to $\mathrm{Al}_{13} \mathrm{Cs}^{-}$. This is the reason why there is a gradual decrease in the electron affinity values as one goes down the group I series from Li to Cs (see Table I and Fig. 6). Similar conclusions can also be reached if one considers the BE equations [Eqs. (2) and (4)]. Thus, the lowering of the $\mathrm{ADE}$ values in going from $\mathrm{Al}_{13} \mathrm{Li}$ to $\mathrm{Al}_{13} \mathrm{Cs}$ is a result of the decrease in the stabilization energy of the corresponding anions.

Next, we consider $\mathrm{Al}_{13} \mathrm{H}$, where the nature of the $\mathrm{Al}-\mathrm{H}$ bond is predominantly covalent. We have recently conducted a thorough investigation on the $\mathrm{Al}_{13} \mathrm{H}^{-} / \mathrm{Al}_{13} \mathrm{H}$ system using a combination of anion photoelectron spectroscopy and DFT computations; ${ }^{27}$ thus, here we will provide only a brief outline of our study. The $\mathrm{H}$ atom has three possible sites where it can bind to the anionic $\mathrm{Al}_{13}{ }^{-}$cluster: the radial or the terminal site where the $\mathrm{X}$ atom is bound to a single $\mathrm{Al}$ atom, the bridge site where it is bound to two $\mathrm{Al}$ atoms, or the hollow site where it resides on the face of a triangle formed by three $\mathrm{Al}$ atoms. We had shown that $\mathrm{H}$ prefers to bind to the terminal site, while its isomer (where $\mathrm{H}$ resides on the hollow site) is $0.64 \mathrm{eV}$ higher in energy. On the other hand, the isomer stability in neutral $\mathrm{Al}_{13} \mathrm{H}$ (structure 3 in Fig. 5) is just the opposite; hydrogen prefers to bind to the hollow site, stabilized by $0.3 \mathrm{eV}$ compared to the radial site. The difference in isomer stability was explained by the fact that in the neutral isomer the capping hydrogen shares its valance electron with aluminum moiety, bringing the total valence electron count to 40 .
The isolobal analogy between gold and hydrogen had been demonstrated in several small clusters where gold is clustered to a nonmetal atom. ${ }^{10-13}$ When bonded to silicon, whose electronegativity is similar to that of hydrogen, gold behaves like hydrogen. ${ }^{10-12}$ It is not immediately clear, however, whether the analogy holds when gold interacts with soft metals such as aluminum. In order to explore this question, we compared the bonding of aluminum with hydrogen and of aluminum with gold. The bond strengths of Al-Au $(3.12 \mathrm{eV})$ and $\mathrm{Al}-\mathrm{H}(3.11 \mathrm{eV})$ are nearly identical, and the charges on their atoms are also very similar. However, the $\mathrm{Al}-\mathrm{Au}$ bond $(2.65 \AA)$ is much longer than the $\mathrm{Al}-\mathrm{H}(1.65 \AA)$, making the dipole moment of the former larger. This makes the $\mathrm{Al}-\mathrm{Au}$ bond more polar than that of Al-H. How do these similarities and differences manifest themselves when $\mathrm{H}$ or $\mathrm{Au}$ interacts with $\mathrm{Al}_{13}$ ? The potential energy surface of $\mathrm{Al}_{13} \mathrm{Au}^{-/ 0}$ differs from that of the corresponding hydride to some extent. Unlike $\mathrm{Al}_{13} \mathrm{H}^{-}$, where the radial isomer is most stable, ${ }^{24}$ in $\mathrm{Al}_{13} \mathrm{Au}^{-}$, the $\mathrm{Au}$ atom prefers to cap a triangular face of $\mathrm{Al}_{13}{ }^{-}$. The radial isomer is $0.33 \mathrm{eV}$ higher in energy. The next lowest energy isomer, which is isoenergetic $(0.01 \mathrm{eV})$ with the ground (triangular face) state, is where Au becomes part of the cage. Note that no such isomer exists for $\mathrm{Al}_{13} \mathrm{H}^{-}$. In the lowest energy isomer of neutral $\mathrm{Al}_{13} \mathrm{Au}$, the gold atom also occupies a triangular face site (see structure 4 in Fig. 5). The Au-inserted isomer (see structure 5 in Fig. 5) is only $0.13 \mathrm{eV}$ higher in energy. In both anion and neutral isomers, the average $\mathrm{Al}-\mathrm{Al}$ bond length is again similar to what is observed in the case of $\mathrm{Al}_{13} \mathrm{M}$ and $\mathrm{Al}_{13} \mathrm{H}$ systems, namely, $2.81 \AA$. Owing to the small energy differences, it is difficult to ascertain the ground state; therefore, we have calculated vertical and adiabatic detachment energies for both in order to compare with experiments. The calculated ADEs (1.98 and $1.97 \mathrm{eV}$ ) for the two isomers match well with the experimental value of the onset of the photoelectron signal (EBE $=2.00 \mathrm{eV})$. The calculated HOMO-LUMO gaps (1.24 and $1.03 \mathrm{eV}$ ) are also in good agreement with the experiment. Note that whether gold occupies a triangular site or becomes part of the cage, the total valence electron count (40 electrons) does not change. In this regard, gold and hydrogen are behaving in a similar fashion. ${ }^{28}$

In conclusion, we have systematically studied the nature of bonding in $\mathrm{Al}_{13} \mathrm{X}$ ( $\mathrm{X}=$ alkali metals, hydrogen, and gold $)$ by employing a combination of anion photoelectron spectroscopy and DFT methods. Despite the wide variation in the nature of the one electron donors, giving rise to ionic ( $\mathrm{Li}-$ $\mathrm{Cs})$, polar covalent $(\mathrm{Au})$, and covalent $(\mathrm{H})$ bonding in $\mathrm{Al}_{13} \mathrm{X}$, the preference to attain electron shell closing (40 electrons) is quite high. In addition, the $\mathrm{Al}_{13} \mathrm{X}$ systems have other features in common as well; structurally, they all maintain a constant average $\mathrm{Al}-\mathrm{Al}$ bond length and, electronically, their HOMO-LUMO gaps are large and similar to one another. Their electron affinities, however, are more sensitive measures of the differences between them. The systematic decrease of the electron affinity values in the $\mathrm{Al}_{13} \mathrm{M}(\mathrm{Li}-\mathrm{Cs})$ clusters (ranging from 1.8 to $1.3 \mathrm{eV}$ ) is mainly due to the decreasing of the anions (41 electrons) compared to their neutral (40 electron) systems. However, in $\mathrm{Al}_{13} \mathrm{Au}$ the electron affinity is $2.0 \mathrm{eV}$, whereas in $\mathrm{Al}_{13} \mathrm{H}$, the two evident 
isomers exhibit values of 1.9 and $2.9 \mathrm{eV}$. Still, all three classes of the $\mathrm{Al}_{13} \mathrm{X}$ clusters are remarkably analogous systems, which together offer an illuminating case study in the differences and similarities caused by varying $\mathrm{X}$ among alkali, hydrogen, and gold atoms.

\section{ACKNOWLEDGMENTS}

This work was supported by Research Corporation (K.B. theory), by the DFG, German Science Foundation (G.G. experiments), and by the (U.S.) Air Force Office of Scientific Research (K.H.B. experiments).

${ }^{1}$ W. D. Knight, K. Clemenger, W. A. de Heer, W. A. Saunders, M. Y. Chou, and M. L. Cohen, Phys. Rev. Lett. 52, 2141 (1984).

${ }^{2}$ M. Y. Chou, A. Cleland, and M. L. Cohen, Solid State Commun. 52, 645 (1984)

${ }^{3}$ M. M. Kappes, R. Kunz, and E. Schumacher, Chem. Phys. Lett. 119, 11 (1985).

${ }^{4}$ M. P. Iñiguez, J. A. Alanso, A. Rubio, M. J. López, and L. C. Basbás, Phys. Rev. B 41, 5595 (1990).

${ }^{5}$ R. E. Leuchtner, A. C. Harms, and A. W. Castleman, Jr., J. Chem. Phys. 91, 2753 (1989).

${ }^{6}$ S. N. Khanna and P. Jena, Chem. Phys. Lett. 219, 479 (1994).

${ }^{7}$ S. N. Khanna, B. K. Rao, and P. Jena, Phys. Rev. B 65, 125105 (2002).

${ }^{8}$ W.-J. Zheng, O. C. Thomas, T. P. Lippa, S.-J. Xu, and K. H. Bowen, J. Chem. Phys. 124, 144304 (2006).

${ }^{9}$ K. Hoshino, K. Watanabe, Y. Konishi, T. Taguwa, A. Nakajima, and K. Kaya, Chem. Phys. Lett. 231, 499 (1994).

${ }^{10}$ B. Kiran, X. Li, H.-J. Zhai, L. F. Cui, and L. S. Wang, Angew. Chem., Int. Ed. 43, 2125 (2004).

${ }^{11}$ X. Li, B. Kiran, and L. S. Wang, J. Phys. Chem. A 109, 4366 (2005).

${ }^{12}$ B. Kiran, X. Li, H.-J. Zhai, and L. S. Wang, J. Chem. Phys. 125, 133204 (2006)

${ }^{13}$ H. J. Zhai, L. S. Wang, D. Yu. Zubarev, and A. I. Boldyrev, J. Phys. Chem. A 110, 1689 (2006)

${ }^{14}$ M. Willis, M. Götz, A. K. Kandalam, G. F. Ganteför, and P. Jena, Angew.
Chem., Int. Ed. Engl. 49 (2010) in press.

${ }^{15}$ O. C. Thomas, W. J. Zheng, T. P. Lippa, S. J. Xu, and K. H. Bowen, J. Chem. Phys. 114, 9895 (2001).

${ }^{16}$ K. Koyasu, M. Akutsu, J. Atobe, M. Mitsui, and A. Nakajima, Chem. Phys. Lett. 421, 534 (2006).

${ }^{17}$ S. Burkart, N. Blessing, B. Klipp, J. Müller, G. Ganteför, and G. Seifert, Chem. Phys. Lett. 301, 546 (1999).

${ }^{18}$ B. K. Rao, S. N. Khanna, and P. Jena, Phys. Rev. B 62, 4666 (2000).

${ }^{19}$ V. Kumar, Phys. Rev. B 57, 8827 (1998).

${ }^{20}$ M. Gerhards, O. C. Thomas, J. M. Nilles, W.-J. Zheng, and K. H. Bowen, J. Chem. Phys. 116, 10247 (2002).

${ }^{21}$ X. Li, A. Grubisic, S. T. Stokes, J. Cordes, G. F. Gantefoer, K. H. Bowen, B. Kiran, M. Willis, P. Jena, R. Burgert, and H. Schnoeckel, Science 315, 356 (2007).

${ }^{22}$ A. Grubisic, H. P. Wang, Y. J. Ko, and K. H. Bowen, J. Chem. Phys. 129, 054302 (2008).

${ }^{23}$ A. D. Becke, J. Chem. Phys. 98, 5648 (1993); C. Lee, W. Yang, and R. G. Parr, Phys. Rev. B 37, 785 (1988); S. H. Vosko, L. Wilk, and M. Nusair, Can. J. Phys. 58, 1200 (1980); P. J. Stephens, F. J. Devlin, C. F. Chabalowski, and M. J. Frish, J. Phys. Chem. 98, 11623 (1994).

${ }^{24}$ M. Dolg, U. Wedig, H. Stoll, and H. J. Preuss, Chem. Phys. 86, 866 (1987); M. Dolg, in Modern Methods and Algorithms of Quantum Chemistry, NIC Series Vol. 1, edited by J. Grotendorst (Jülich Research Center, Jülich, 2000); T. Leininger, A. Berning, A. Nicklass, H. Stoll, H.-J. Werner, and H.-J. Flad, Chem. Phys. 217, 19 (1997); W. Kuchle, M. Dolg, H. Stoll, and H. Preuss, Pseudopotentials of the Stuttgart/Dresden Group (Revision: Tuesday, August 11, 1998), 1998. See http:// www.theochem.uni-stuttgart.de/pseudopotentiale.

${ }^{25}$ M. J. Frisch, G. W. Trucks, H. B. Schlegel et al., GAussian 03, Revision B.05, Gaussian, Inc., Pittsburgh, PA, 2003.

${ }^{26}$ B. Kiran, P. Jena, X. Li, A. Grubisic, S. T. Stokes, G. F. Gantefoer, K. H. Bowen, R. Burgert, and H. Schnöckel, Phys. Rev. Lett. 98, 256802 (2007).

${ }^{27}$ A. Grubisic, X. Li, S. T. Stokes, K. Vetter, G. F. Gantefor, K. H. Bowen, P. Jena, B. Kiran, R. Burgert, and H. Schnöckel, J. Chem. Phys. 131, 121103 (2009).

${ }^{28}$ For reviews on auride chemistry, see P. Pyykkö, Angew. Chem., Int. Ed. 41, 3573 (2002); L. Gagliardi, J. Am. Chem. Soc. 125, 7504 (2003). 